\title{
Vendo, sentindo e tocando: processos de musicalização de crianças surdas
}

\author{
Seeing, feeling, touching: Processes of musicalization for \\ deaf children
}

Regina Finck Schambeck* regina.finck@udesc.br 


\section{Resumo}

Para evidenciar o processo de aprendizagem musical de crianças surdas no contexto inclusivo, este artigo compartilha princípios educativos que orientaram uma prática pedagógica de musicalização. Com ênfase na pesquisa-ação e a partir da adaptação de materiais e recursos pedagógicos, a aprendizagem musical significativa foi proporcionada para alunos surdos e ouvintes, em um mesmo ambiente educativo. Para orientar essas práticas, foram selecionados autores que levassem em conta os processos cognitivos diferenciados dos alunos surdos, ou seja, que considerassem que as atividades musicais devem ser desenvolvidas com ênfase nos processos de ver, ouvir/sentir e tocar, o que remete aos estímulos acústicos, vibratórios, táteis, emocionais e sociais. Ao adaptar as atividades musicais, caminhos alternativos foram seguidos para instigar o crescimento musical dos alunos com surdez. A análise dos dados demonstrou que as práticas contribuíram para ampliar as discussões sobre aprendizagens musicais das crianças surdas. Ao mesmo tempo, a pesquisa apontou alguns parâmetros de ação inclusiva que podem ser incluídos nos cursos de Licenciatura em Música e na formação continuada de professores, tal como já é preconizado nos documentos normativos de formação, estabelecidos pelas políticas públicas brasileiras. É dever das instituições formadoras prever ações de qualificação dos profissionais envolvidos tanto nos aspectos da educação musical, como, também, da instrução dos conteúdos de formação humanística e relativos à educação especial como um todo.

Palavras-chave: Educação musical; Crianças surdas; Inclusão.

\section{Abstract}

This article seeks to find evidence to show how musical learning of deaf children takes place in an inclusive learning environment, with a view to share educational principles which set out guidelines for teaching practices of musicalization. While laying emphasis on action research, an attempt has been made to provide significant musical learning for both deaf and normal-hearing students in the same educational environment, by adapting the necessary materials and pedagogical resources. Putting these practices into effect required finding authors who took into account the different kinds of cognitive processes suitable for deaf students or, in other words, musical activities carried out with an emphasis on the senses of seeing, hearing/feeling and touching. These senses involve acoustic, vibratory, tactile, emotional and social stimuli. In adapting the musical activities, alternative measures are employed to foster a growth in musical awareness among the students with hearing impairment. The data analysis showed that these practices have led to a wider discussion on the musical learning of deaf children. At the same time, the research defined some parameters of inclusive action which can guide the direction of planned degree courses in music and continuous teacher-training, such as those recommended in the standardized regulations for training and policymaking in Brazil. It is the responsibility of educational institutions to take measures in advance that can lead to the qualification of teachers involved in areas of musical education and in preparing instructive material that is suitable for general humanist training as a whole, while catering to the needs of special education.

Keywords: Musical education; Deaf children; Inclusion. 


\section{Introdução}

Este texto surgiu a partir do trabalho de musicalização, realizado com crianças surdas, com a adoção de diferentes procedimentos relacionados ao emprego da música e do movimento. Nesse trabalho, inicialmente, estudou-se a literatura sobre a temática, chegando-se aos escritos de autores do contexto brasileiro, que já tinham estudos publicados na área de arte e surdez, quais sejam, Nadir Haguiara-Cervelini $(2003,1983)$, Sarita Pereira (2004) e Viviane Louro (2006), que foram a base inicial para a introdução aos estudos. Além dessas autoras, trabalhos de especialistas na área de musicalização de pessoas surdas, como Evelyn Glennie $(2006,2003)$, Shirley Salmon $(2006,2003)$, Alice Ann Darrow (2007, 1996), Naomi Benari (2004) e Eleonor Edwards (1974) foram fundamentais para o estabelecimento dos processos a serem adotados para ensinar música em contexto de inclusão. Conhecer essas produções literárias foi importante para sair do modo ouvinte, a partir do qual se tem dificuldades em compreender o que significa ter deficiência auditiva ou em identificar, em um nível mais amplo, que experiências e/ ou limitações os indivíduos enfrentam para musicalizarem-se, estando sob a condição da surdez.

Assim, ao entrar em contato com a literatura que aborda o tema música e surdez, ficou claro que ouvir/sentir e tocar remetem aos estímulos acústicos, vibratórios, táteis, emocionais e sociais. Por trás de ouvir, como afirma Salmon (2006), está implícita a atividade individual e ativa de ouvir com atenção. Ou seja, ouvir é algo que não acontece somente através dos ouvidos, mas também pelo corpo todo, pois a percepção vibrotátil amplia o que se ouve pelo ouvido. Do mesmo modo, o sentir é descrito pela autora como algo que pode significar tanto estímulos vibratórios, táteis, emocionais ou sinestésicos, como também o lado emocional, do sentimento. Então, tocar, sob essa perspectiva, refere-se não somente ao tocar instrumentos, ao fazer musical, mas também à vivência de estórias ou brincadeiras com movimento.

O princípio educativo que guiou a prática musical com crianças surdas perpassou por questionamentos que levaram em conta a necessidade de identificar através de que caminho ou abordagem seguir, qual atividade praticar, através de quais métodos e de que forma de participação ocorreriam as ações, se com música e/ou movimento as crianças teriam, de fato, maior aproveitamento dos seus processos de musicalização.

O texto foi, então, organizado de modo que, na primeira parte, há uma introdução à pesquisa; nos fundamentos práticos, da segunda parte do texto, apresentam-se os princípios educativos que nortearam a proposta; e, na última parte do texto, apresentam-se as atividades que fizeram parte da oficina Sons em Movimento, realizada com alunos surdos e ouvintes em contexto inclusivo.

\section{Fundamentos práticos/princípios educativos}

Como analisar se a participação de surdos no âmbito da música é ou não significativa? Olhando para os seus processos de aprendizagem: é o som música ou é a música som? Ao responder a essas perguntas, Glennie (2006) remete-se à filosofia da língua 
italiana, a qual usa o mesmo verbo tanto para ouvir quanto para sentir a música. Essa autora compreende como sendo falsa a suposição de que só existiria a música se fosse ela percebida somente pelo ouvido humano.

Para ela, a pessoa ouvinte usa os três sentidos para escutar, ou seja, a visão, o toque e a audição; já o surdo utiliza apenas dois desses sentidos: o toque, através da sensação, e a visão. O verbo "escutar", em sua raiz semântica, engloba três ações: o ouvir, o sentir e o ver. Já o verbo "ouvir" envolve apenas a ação orgânica específica do aparelho auditivo. Desse modo, para que o surdo profundo possa escutar, ele teria que ouvir os sons e sentir as vibrações. Nas palavras da autora:

[...] ouvir é basicamente uma forma especializada de toque. O som é, simplesmente, $o$ ar vibrando que o ouvido colhe e converte em sinais elétricos e que, então, são interpretados pelo cérebro. A sensação do ouvir não é o único sentido que pode fazer isto, o toque pode fazer isto demasiado. Se você estiver em uma estrada e um caminhão grande passar por perto, você ouve ou sente a vibração? A resposta é ambos. Com a vibração de frequências muito graves o ouvido começa a se transformar ineficiente e o resto do sentido de toque do corpo começa a dominar. Por alguma razão nós tendemos a fazer uma distinção entre o ouvir um som e o sentir uma vibração, que na realidade são a mesma coisa. É interessante notar que na língua italiana esta distinção não existe. O verbo "sentire" significa ouvir e o mesmo verbo na forma reflexiva "sentirsi" significa sentir. A surdez não significa que você não pode ouvir, apenas que há algo errado com o ouvido. Mesmo alguém que é totalmente surdo pode ainda ouvir/sentir sons. (GLENNIE, 2015, tradução nossa).

Contudo, há um outro elemento na equação de escutar: a visão. A partir da visão, pode-se também ver os objetos movendo-se e vibrando. Ao ver a pele de um tambor vibrar, ou mesmo ao ver as folhas de uma árvore que se movem ao vento, o cérebro cria um som correspondente. Para Glennie, o processo de escutar está intimamente relacionado aos outros sentidos, que teriam a função adicional de processar os vários "bits" das informações geradas pela emissão de um sinal elétrico para, só então, criar uma imagem do som. A autora afirma que os vários processos envolvidos em escutar um som são muito complexos e realizados subconscientemente.

É consenso que tocar um instrumento seja um aspecto importante para se fazer a música, mas Glennie (2006) destaca que a experiência da transformação física que ocorre ao se escutar um instrumento tocado ao vivo é imensamente importante para quem é surdo, pois diz ela que "[...] a música tem o seu lugar, definitivamente, na forma de arte viva, que respira, a qual devemos nos abrir, para que juntos possamos tomar parte dela e aprender com ela" (GLENNIE, 2006, p. 7). A autora se refere ao momento importante de audição ao vivo, que ela explica como sendo "[...] aquele momento do contato com a produção instrumental" (idem).

Nesse sentido, uma audição musical unidimensional, apenas com o ouvido, mesmo que feita sob as melhores condições acústicas, não seria capaz de proporcionar aos surdos uma experiência de corpo inteiro. "Confiar apenas em nossos ouvidos seria comparado ao 'comer sem saborear'" (idem). Esse entendimento levou à observação de que o aumento explosivo de possibilidades de acessar gravações e vídeos pela internet 
ou outros meios técnicos, em detrimento do recital ou do concerto acústico, conduziu a uma mudança na capacidade de ouvir ou de ouvir com atenção. Atualmente, é desejável que, além de ouvir, todos os outros sentidos sejam estimulados, o que não ocorre quando o som é produzido mecanicamente, mediante o uso de aparelhos de reprodução sonora.

Sob essa lógica, se alguém não se encaixa na categoria de ouvinte, como o surdo, subentende-se que este indivíduo seria imediatamente considerado como alguém que não pode ouvir música no seu sentido convencional. Sobre isso, Glennie (2006, p. 8) conclui o seu argumento reforçando o princípio educativo de "ouvir com atenção e sentir com atenção". Essa ação complexa de ouvir com o corpo todo extrapolaria o processo implicado na ação de uma simples reprodução sonora, o que foi identificado no referido trabalho de musicalização de que trata este artigo, realizado com o grupo de crianças surdas e ouvintes em contexto inclusivo.

Ao abordar uma proposta de educação musical para crianças surdas e ouvintes, partiu-se do pressuposto de que, no processo de aprendizagem delas, não haveria diferença se o indivíduo fosse ouvinte ou não ouvinte, pois, nesse processo, sempre seria possível valorizar detalhes do som, por causa da capacidade de perceber coisas de forma mais profunda do que apenas o uso do ouvido para ouvir. E aqui, novamente, um pressuposto de Glennie (2006) foi colocado em prática, qual seja, o de que, nos processos de aprendizagem musical para surdos, é preciso propor atividades significativas para eles, ou seja, atividades que os façam usar o corpo todo como caixa de ressonância.

\subsection{Experiências significativas em música}

A expressão experiências significativas em música é aqui entendida a partir da concepção de Edwards (1974). Ela diz que o que torna significativa uma experiência musical para o aluno surdo é a possibilidade de ele construir o conhecimento musical a partir dos conceitos musicais, ou seja, "[...] se a finalidade de ensinar a música ao surdo for fazê-lo aprender algo sobre a música, então se deve ensinar música a ele" (EDWARDS, 1974, p. 100).

Em um estudo de caso, Cruz (1997) examinou a perspectiva de um professor de música ao trabalhar com um aluno surdo em sala de aula. Os resultados da pesquisa sugerem que, se a música for apresentada em um contexto significativo, pode representar um papel muito importante na aprendizagem do aluno e, principalmente, na integração social das crianças surdas.

Segundo Brown e Denney (1997), a música pode beneficiar uma criança surda em muitas áreas de sua vida, promovendo experiências denominadas como significativas e que farão parte da identidade cultural, que será construída também a partir disso. Assim, sem exposição à música, à sua história e aos seus compositores, as crianças surdas perderão uma parte valiosa da instrução cultural. Para as autoras, os sentidos remanescentes podem ser utilizados pelos indivíduos surdos para compreender e apreciar a música. Por exemplo, um indivíduo surdo pode apreciar a música através da estimulação tátil e visual. A música pode também ser usada como uma ferramenta de relaxamento para as 
crianças que estão tensas ou com hiperatividade.

No exemplo da instrução da linguagem musical, sugerido por Salmon (2003), entende-se que a música deva ser usada não unicamente para expressar os movimentos do corpo, mas também como uma parte significativa da atividade de aprendizagem. A maneira como a música se torna significativa para os indivíduos surdos precisa ser, contudo, melhor explorada.

Nesse sentido, Edwards (1974) enfatiza que os conceitos musicais deverão estar presentes nas atividades a serem desenvolvidas com as crianças surdas. A atividade musical significativa possibilita que elas construam conceitos musicais, expressando-os em seguida, a partir de uma execução sonora. Assim, estratégias de aprendizagem que privilegiam o conceito como o gerador da prática musical podem ser empregadas pelo professor como recurso metodológico.

Autores como Edwards (1974), Darrow e Schunk (1996) e Hash (2003) sugerem que, ao adaptarem as práticas pedagógicas às necessidades do aluno surdo, ao mesmo tempo em que se fornece a ele a oportunidade de experimentar a música em uma maneira concreta, torna-se mais significativo o processo dele de aprender e de apreciar a música. De outro modo, sem a oportunidade de experimentar a música, essas crianças surdas não poderão incorporá-la ao seu projeto de vida, nem mesmo experimentá-la para emitir um juízo de valor.

Contudo, como afirma Darrow (2007), uma experiência significativa depende, fundamentalmente, da qualificação dos profissionais envolvidos, o que requer uma preparação tanto nos aspectos da educação musical, como, também, da instrução dos conteúdos de formação humanística e relativos à educação especial como um todo.

\subsection{O planejamento da aula de música para surdos}

Para manter os estudantes interessados e envolvidos nas atividades com a música, procura-se constantemente por novas maneiras de aproximar-se dos conceitos musicais através de atividades práticas. A pesquisa de Hash (2003), nesse sentido, sugere que, para a realização das atividades práticas com alunos surdos, poderiam ser utilizados instrumentos de diversos tamanhos e timbres de boa qualidade sonora. É o caso, por exemplo, das propriedades do som. O autor também menciona a utilização de recursos oriundos dos avanços tecnológicos, explicando que a quantidade de softwares de música aumentou significativamente e que a utilização desses recursos da computação poderia fornecer, além de indícios visuais para alguns dos sons musicais, até mesmo a amplificação de sensações vibrotáteis com efeitos cinestésicos, permitindo a percepção corporal desses sons. Há também relatos em Pereira (2016) de pesquisas que se utilizam de recursos tecnológicos para ampliar a percepção vibrotátil de surdos.

Contudo, tecnologias à parte, o planejamento das atividades musicais, direcionadas às crianças surdas, deverá apontar também para outros caminhos. Entre eles, para a utilização de instrumentos musicais, de modo que eles não se constituam somente como uma ferramenta para aumentar a motivação das crianças, mas que também deem suporte para a aprendizagem musical delas. 
Nas atividades sugeridas por Edwards (1974), Haguiara-Cervellini (1983), Cruz (1997), Hash (2003), Salmon (2003) e Darrow (2007), a utilização de instrumentos ativaria o princípio do jogo e, assim, as experiências musicais poderiam ser executadas com sucesso por crianças surdas.

Os métodos de ensino deverão ser adaptados e modificados para que o aluno surdo possa tocar com técnica. De acordo com Edwards (1974), as partituras a serem utilizadas deverão estar adaptadas com as sugestões visuais e estimulação tátil. Para a autora, ao ensinar música instrumental aos estudantes surdos, conclui-se que as exigências para aprender um instrumento são similares para ambos: surdos e/ou ouvintes. Ela diz que, "[...] para todos os alunos é necessário um ensino bom, uma prática consistente e uma sustentação positiva" (EDWARDS, 1974, p. 121).

Robbins e Robbins (1980) apontam, ainda, para a necessidade da elaboração de arranjos específicos para a execução de alunos surdos. Para os autores, as peças podem necessitar de arranjos mais simplificados para compensar uma falta do desenvolvimento técnico em um primeiro momento de musicalização. Contudo, não se quer aqui afirmar que arranjos simplificados sejam utilizados de maneira recorrente. À medida que os alunos desenvolverem suas aprendizagens musicais, evidentemente, os arranjos ganharão níveis mais complexos de elaboração.

Para Salmon (2003), os métodos que envolvem o princípio de aprender fazendo, com a ênfase na experiência sensório-extensiva, são cruciais para o desenvolvimento do sentido neuromuscular das crianças surdas para a música. Assim, em consequência da exposição às experiências concretas com música, a partir desse aprender fazendo, as crianças podem desenvolver sentimentos e construir imagens mentais dos conceitos da música, gerando essa compreensão.

Em se tratando do ensino de música, sabe-se que o indivíduo surdo tem uma posição desvantajosa com relação ao indivíduo ouvinte. De acordo com a revisão da literatura, para ajudar um indivíduo surdo a construir seus próprios conceitos da música e a compreendê-los, é preciso ensiná-lo música fazendo com que ele, para isso, utilize todo o seu corpo, através dos seus movimentos. Dessa forma, através de atividades em que o movimento é estimulado, todas as crianças, incluindo as crianças surdas, poderão perceber as vibrações musicais, os ritmos e a dinâmica musical. De acordo com Salmon (2003) e Benari (2004), o movimento e a música, quando usados conjuntamente, motivam e ajudam a criança a controlar o seu próprio corpo e podem constituir-se como um meio particularmente valioso para promover a expressão musical de uma criança surda.

Salmon (2003) também sugere que se faça uso da música e do jogo como possibilidades de reunir, de modo lúdico, música e brincadeira. É através do jogo e da relação com os colegas que são estabelecidas as regras de convivência e que se aprende a lidar com as regras de jogo. Segundo a autora, música, jogo e movimento vêm sendo utilizados por muitos anos nos processos de musicalização de crianças, principalmente pela resposta corporal delas, muito natural à música. Essas respostas podem ser evidenciadas nas ações corporais das crianças, como em um andar mais estereotipado pelo som, ou num saltar estimulado pelo ritmo, num pular acompanhado do sorriso de quem está sentindo a vibração do som, e assim por diante. E Salmon (2003) ainda aponta o 
caminho para isso, mostrando a existência de músicas que naturalmente sugerem esses movimentos, como, por exemplo, acenar como árvores ao vento, flutuar como nuvens, cair adormecido e acordar quando a música sugerir que assim seja feito, ou ainda executar outros movimentos que são percebidos através da sua execução. Sob esse ponto de vista, a liberdade de movimentos e a liberdade pessoal devem ser incentivadas em todos os níveis de educação, pois é essa liberdade que permite às crianças responderem fisicamente aos movimentos.

Ao tratar da questão do movimento e da dança para a criança surda, Benari (2004) sugere que se faça uma introdução aos conceitos musicais. Em sua obra Inner Rhythm (Ritmo Interno), ela destaca a importância da expressão corporal para o surdo e a íntima relação da dança com a música, não havendo, portanto, segundo a autora, qualquer justificativa para não se oportunizar dança e música ao surdo.

Por que não? Quase todos gostam de dançar e mover-se. Por que o surdo deve ser privado desse prazer? Por que não proporcionar também para as crianças surdas os benefícios, físico, metal, emocional e estético da dança, como é feito para as crianças ouvintes? Dança e entusiasmo atestam o sentimento de bem- estar que se deriva da prática dessa atividade. (BENARI, 2004, p. 16, tradução nossa).

Ela sugere, ainda, vários tópicos para orientar um professor de dança no trabalhar com os elementos musicais que nortearão a sua prática com alunos surdos, pois entende que dança e música estão intimamente ligadas e reforça esse elo mencionando o fato de que, em algumas culturas, existe uma única palavra para designar a dança e a música. Esse é o seu princípio norteador, ou seja, o de que as pessoas não fazem a música sem dançar, nem a dança sem fazer música (BENARI, 2004).

A autora afirma que o movimento pode, ainda, melhorar a flexibilidade e a força física do aluno surdo e que a dança também pode ampliar a possibilidade de aprimoramento da autoexpressão e da criatividade. Ela explica também que, segundo o seu ponto de vista, a dança pode aumentar o conhecimento do espaço e da posição do corpo em relação a ele; dançar com um parceiro ou em grupo pode aumentar a sua consciência da sua sociabilidade e a dos outros em geral. O ritmo interno pode expandir sua compreensão sobre ritmo, e a respiração profunda, por sua vez, pode ajudar no desenvolvimento da sua fala. A aquisição da autodisciplina pela dança pode se constituir como uma ferramenta benéfica para outras áreas de conhecimento (BENARI, 2004).

Assim, fundamentando-se nas propostas aqui apresentadas, de Salmon (2003) e Benari (2004), conclui-se que, se o professor de dança pode utilizar esta linguagem para uma introdução à música, o professor de música poderia, também, valer-se da dança e do movimento para desenvolver as habilidades relacionadas a uma aprendizagem musical, como a identificação e a contagem de pulsos, a consciência espacial, o entendimento da forma da música, da exploração do balanço e do equilíbrio, por exemplo.

Para o planejamento de aulas de música para surdos, há também algumas abordagens tradicionais. Edwards (1974), por exemplo, cita especificamente as abordagens de Orff e Kodály, sugerindo a utilização de componentes visuais de movimento, abordados 
por esses dois educadores, para ensinar conceitos musicais aos alunos surdos. Para ela, todos os educadores musicais deveriam dedicar atenção especial à amplificação do estímulo musical, utilizando-se, para isso, dos recursos fonomímicos, destacados pelos respectivos autores. Edwards (1974) também destaca como sendo fundamentais os aspectos relativos à qualidade de instrumentos e equipamentos de gravação e à familiaridade e complexidade dos materiais usados.

Alunos com surdez mais profunda conseguem ouvir ruídos de vários tipos e serem sensíveis a vibrações de toda espécie. Essa sensibilidade às vibrações pode tornar-se um tipo de sentido acessório, conforme explica Sacks (2005), que utiliza essa expressão, sentido acessório, para se referir ao desenvolvimento da percepção de vibrações pelos indivíduos surdos. Para exemplificar essa capacidade de identificar vibrações, ele cita o exemplo de uma aluna surda, Lucy K., que, embora profundamente surda, era capaz de avaliar, de imediato, um acorde como dominante, colocando a mão sobre o piano. Além disso, conseguia interpretar vozes em telefones com grande amplificação. Em ambos os casos, o que se percebeu foram vibrações, e não sons. Para Sacks (2005, p. 21), esse sentido acessório "[...] guarda certas analogias com o desenvolvimento da 'visão facial' - que usa o rosto para receber uma espécie de informação de sonar - nos cegos". Ele também defende a utilização de aparelhos de amplificação sonora, entendendo que esses aparelhos representam um grande avanço ao propiciar aos alunos surdos experiências significativas em música, pois facilitam a percepção do mundo sonoro. Por todo o corpo, a partir dessas ferramentas, é possível captar as vibrações das ondas sonoras, que podem ser percebidas tanto pela pele quanto pelos ossos.

John Macy, comentando os processos que Keller (2001) descreveu na obra A história de minha vida, afirma que, em relação à música, as vibrações sonoras eram importantes, não sendo possível, porém, fazer um juízo exato de suas sensações:

\begin{abstract}
Quando alguém toca música, sua fisionomia exprime entusiasmo; ela aplaude juntamente com os outros espectadores [...]. A música desperta na Srta. Keller, a idéia de ruído e ritmo. Mesmo não sabendo cantar nem tocar ela experimenta algum prazer com a arte dos sons. As vibrações lhe chegam pelos corpos sólidos em que ela pousa a mão, ou mesmo pelo ar. Ela gosta, igualmente, de apalpar a garganta de uma pessoa que canta, para sentir a vibração e o movimento dos músculos. (KELLER, 2001, p. 180).
\end{abstract}

Para Haguiara-Cervellini (2003), a qualidade da produção sonora da criança surda será diferente se ela tiver contato com a música. Independentemente do grau da perda auditiva, as crianças surdas são sensíveis à música. Para a autora, a vivência com essa arte torna visível a descontração, a liberdade, a criatividade, a comunicação, a afetividade e a alegria das crianças. Em sua pesquisa, ela relata a relevância da música para a vida dos sujeitos surdos, apontando o quanto isso favorece o "[...] desenvolvimento integral da pessoa" (HAGUIARA-CERVELLINI, 2003, p. 81).

A flexibilização dos processos de ensino da música para crianças surdas vem sendo discutida por educadores como um meio para facilitar a aprendizagem. Essa plasticidade aplicada no planejamento seria necessária, pois permitiria uma adaptação às necessidades dos alunos em todo o processo de ensino/aprendizagem. A necessidade 
dessa flexibilização de planejamento deriva-se da complexidade dos processos educativos que dificilmente podem ser previstos com antecedência. Por isso, a importância de contar com um número de meios e estratégias para poder atender às diferentes demandas que aparecerão no transcurso do processo de ensino/aprendizagem.

Nesse sentido, deve fazer parte das características de um professor ter uma boa percepção para notar, por exemplo, se a atividade deve ser modificada ou, até mesmo, abandonada, quando não estiver cumprindo os objetivos estabelecidos previamente. Como afirma Cruz (1997), a razão para mudar as atividades é que a maioria dos estudantes surdos tem atenção reduzida. Contudo, para manter sua atitude positiva para a música, é necessário mudar a atividade constantemente ou parar, quando não estiverem mais interessados: "[...] se estão aceitando [a atividade musical], fazê-la; se não, mudá-la" (CRUZ, 1997)1. Da mesma maneira, Salmon (2003), também destaca a necessidade de o professor de música ser flexível para trocar a atividade, caso ela não esteja cumprindo o objetivo inicialmente previsto. Para as duas autoras, um professor com planejamento flexível poderá evitar que os estudantes fiquem cansados ou desmotivados para a realização das atividades propostas.

As condições de trabalho e do espaço físico também são importantes e devem ser consideradas no planejamento, dada a natureza da expressão corporal a ser realizada com alunos surdos. Desse modo, é importante que o espaço a ser utilizado esteja adaptado e tenha um isolamento acústico para as atividades musicais direcionadas aos surdos.

De acordo com Haguiara-Cervellini (1983), Edwards (1974) e Benari (2004), na impossibilidade de um estrado, é recomendável, então, a utilização de um espaço que tenha um assoalho de madeira. $O$ assoalho de madeira é indicado pois facilita a condução das vibrações sonoras até o corpo da criança surda, permitindo, desse modo, sentir melhor as condições acústicas do ambiente. Nesses locais, também é indicado que se use roupas mais leves e que os pés estejam descalços.

A partir da revisão da literatura, foi possível perceber que a questão da educação musical para surdos vai muito além das salas de aula nas escolas regulares. Acredita-se que, a partir da compreensão das significações sociais sobre a relação surdez-música, todo o contexto sociocultural vivenciado pela cultura surda pode ser melhor compreendido e absorvido. Conhecer esse contexto ajudou fundamentalmente esta pesquisadora no planejamento e na execução das ações práticas de atividades musicais direcionadas para alunos surdos em contexto inclusivo.

\section{Proposta de ensino musical para alunos surdos}

Propondo-se um ensino musical para surdos, pressupõem-se transformações das representações já estabelecidas. Acredita-se que ser musical não é privilégio de seres especiais e bem-dotados, mas é uma possibilidade do homem como ser, como foi discutido e apresentado nos tópicos anteriores. A revisão dessas concepções pode dar novas perspectivas para o tema quando ele começar a transitar pelas estruturas sociais. 
Ou seja, oportunizar experiências musicais para surdos pode contribuir para essas mudanças.

Ratificando, para que as práticas musicais sejam significativas para as crianças surdas, é preciso que sejam adotados processos cognitivos diferenciados. Um dos primeiros pontos a ser compreendido é o da percepção. $O$ aluno surdo é fundamentalmente visual. Assim, partindo-se do pressuposto de que é a percepção visual que importa para o indivíduo surdo, quando se pensa em musicalizar uma criança surda, em um primeiro momento, defronta-se com a barreira ideológica quase que intransponível. Assim, se está embutida a ideia de que, para ser musical, é necessário ser ouvinte, pensar o indivíduo surdo como ser musical pressupõe a revisão de concepções já estabelecidas, pois, afinal, no caso dos surdos, é o olho, e não o ouvido, que tem a pretensão de ver as palavras. São as mãos, e não as cordas vocais, que as articulam. Então, como trabalhar a linguagem musical sem considerar que o ouvido e as cordas vocais são os órgãos mais utilizados para expressá-la? O educador musical depara-se com o dilema, diante da criança surda, de perceber-se de imediato como impotente: como ensinar, se cantar não pode ser mais o meio? Como ensinar linguagem musical sem usar o som?

Para aliviar essa tensão de não saber o que fazer nem como fazer, Edwards (1974) e Salmon (2003) fornecem os fundamentos básicos do ensino musical voltados aos alunos surdos. Para as autoras, experiências musicais gratificantes na infância podem ser fundamentais para a constituição do ser musical de uma pessoa surda.

\begin{tabular}{|ll|}
\hline 1. & Habilidades rítmicas tendem a ser mais fortes do que habilidades relacionadas à fala. \\
\hline 2. & A discriminação de padrões rítmicos é mais difícil do que a percepção do pulso. \\
\hline 3. & O estímulo musical pode ser apresentado em um nível apropriado de amplificação. \\
\hline 4. & A percepção tátil pode compensar em parte o déficit auditivo. \\
\hline 5. & Dicas visuais para representar o pulso podem ser particularmente úteis. \\
\hline 6. & $\begin{array}{l}\text { As discriminações de alturas podem ser percebidas mais facilmente em uma } \\
\text { abrangência de frequências graves. }\end{array}$ \\
\hline 7. & As habilidades de discriminação de altura podem ser desenvolvidas com treinamento. \\
\hline 8. & $\begin{array}{l}\text { Habilidades de discriminação podem ser mal julgadas por causa dos problemas de } \\
\text { linguagem, que interferem nas habilidades dos estudantes em descrever o que é } \\
\text { ouvido. }\end{array}$ \\
\hline 9. & $\begin{array}{l}\text { A abrangência vocal dos estudantes com perdas auditivas é frequentemente mais } \\
\text { baixa e mais limitada do que a apresentada por estudantes ouvintes. }\end{array}$ \\
\hline 10. Os alunos com perdas auditivas são frequentemente mais capazes de responder aos \\
aspectos rítmicos da música do que aos aspectos tonais. \\
\hline 11. Instrumentos temperados podem dar um melhor retorno aural do que os instrumentos \\
de percussão.
\end{tabular}


14. O estímulo vibrotátil é uma ferramenta suplementar útil na instrução de música de estudantes com perdas auditivas, como são também para os alunos típicos ouvintes.

15. Com o tempo, estudantes com perdas auditivas podem desenvolver um ouvido mais sensível ao som.

16. Alunos com perdas auditivas exibem certas preferências musicais com relação ao som, à fonte, à intensidade e às condições de escutar.

17. Deveria ser dada uma atenção particular para a amplificação e a qualidade musical da mídia musical quando se instrui alunos com perdas auditivas.

18. A instrução musical pode ajudar no desenvolvimento de um número de comportamentos não musicais, como a produção da fala e da escuta, linguagem, habilidades sociais e acadêmicas.

Quadro 1 - Fundamentos do ensino musical para alunos surdos

Fonte: Adaptada de Edwards (1974) e Salmon (2003).

Os fundamentos apontados pelas autoras deixam em evidência que a música é um elemento inestimável para a formação e para o desenvolvimento da sensibilidade da criança surda. Os pressupostos mostram a importância de propiciar a música de forma lúdica e prazerosa na infância, para que a criança surda possa apropriar-se dela.

\subsection{Como a criança surda se relaciona com as práticas musicais: sugestões de atividades}

A partir do trabalho realizado com as crianças surdas em forma de oficina, destacam-se aqui as experiências vivenciadas por elas, consideradas as mais significativas conforme julgamento desta autora. Deve ser levado em consideração que essas atividades aconteceram durante um semestre, em um total de 15 encontros, que aconteceram uma vez por semana com duas horas de duração cada.

Foram estruturados dois blocos distintos de conteúdos: a percepção sonora, através do contato com o som, seja em forma de apreciação ou produção; e a organização desse material sonoro. O primeiro bloco diz respeito à escuta ativa dos sons do entorno, presentes no cotidiano. O segundo bloco envolveu a organização dos elementos de percepção sonora que ampliaram a capacidade de expressão corporal ou pela utilização de objetos sonoros e/ou instrumentos musicais.

Aprofundou-se, no primeiro bloco, o entendimento sobre o processo de conscientização do entorno sonoro. Para isso, foram utilizados os aspectos já desenvolvidos em trabalho de mestrado desta autora (FINCK, 2001) e que foram adaptados para essa nova realidade. Os princípios educativos foram assim definidos: exploração sonora, experimentação sonora, estruturação gráfica e interpretação (leitura e execução). 


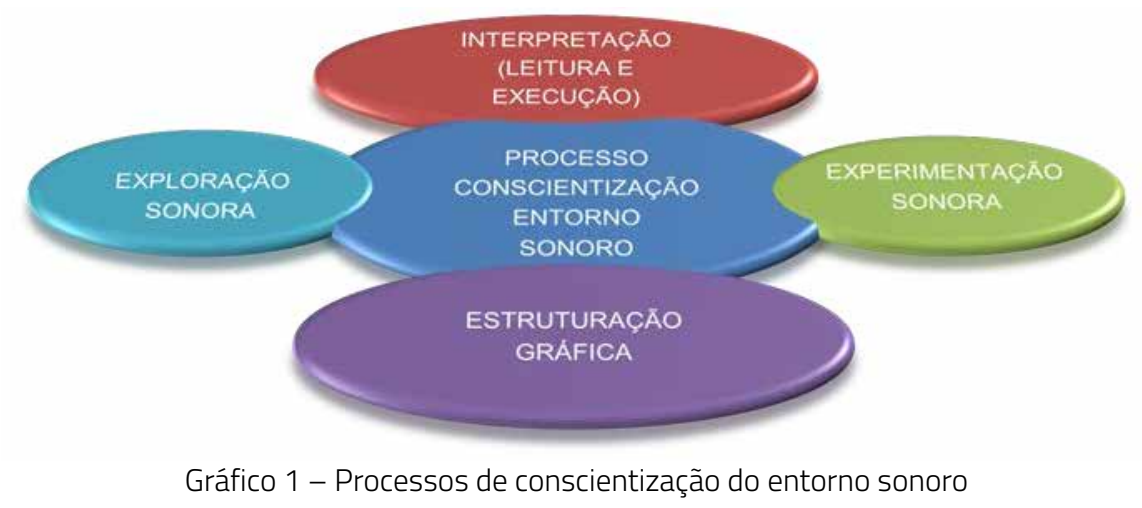

Fonte: Elaborado pela autora (2009).

O primeiro processo de conscientização do entorno sonoro caracterizou-se pela aplicação do primeiro princípio educativo, qual seja, a exploração livre dos instrumentos disponibilizados na sala. Era preciso que alunos surdos tivessem um contato físico com essas vibrações. Várias atividades foram criadas e recriadas para proporcionar vivências com o material sonoro, desde a livre exploração dos objetos até a sua percepção no ambiente natural. Gestos, expressões corporais e sinais gráficos foram empregados para sensibilizar o grupo para a presença do som ou a sua ausência. Foi a partir dessa exploração que se estabeleceram algumas referências para pulso e sua subdivisão, por exemplo. Fazem parte desse princípio a possibilidade do contato real com a atividade musical, a partir das percepções vibrotáteis com a utilização de instrumentos acústicos e/ou a utilização de caixas de amplificação com potência para que as sensações pudessem chegar até a criança surda por diferentes partes do corpo (mãos, pés, costas, tórax, entre outros). As imagens a seguir elucidam os processos utilizados em diferentes momentos do trabalho de musicalização.
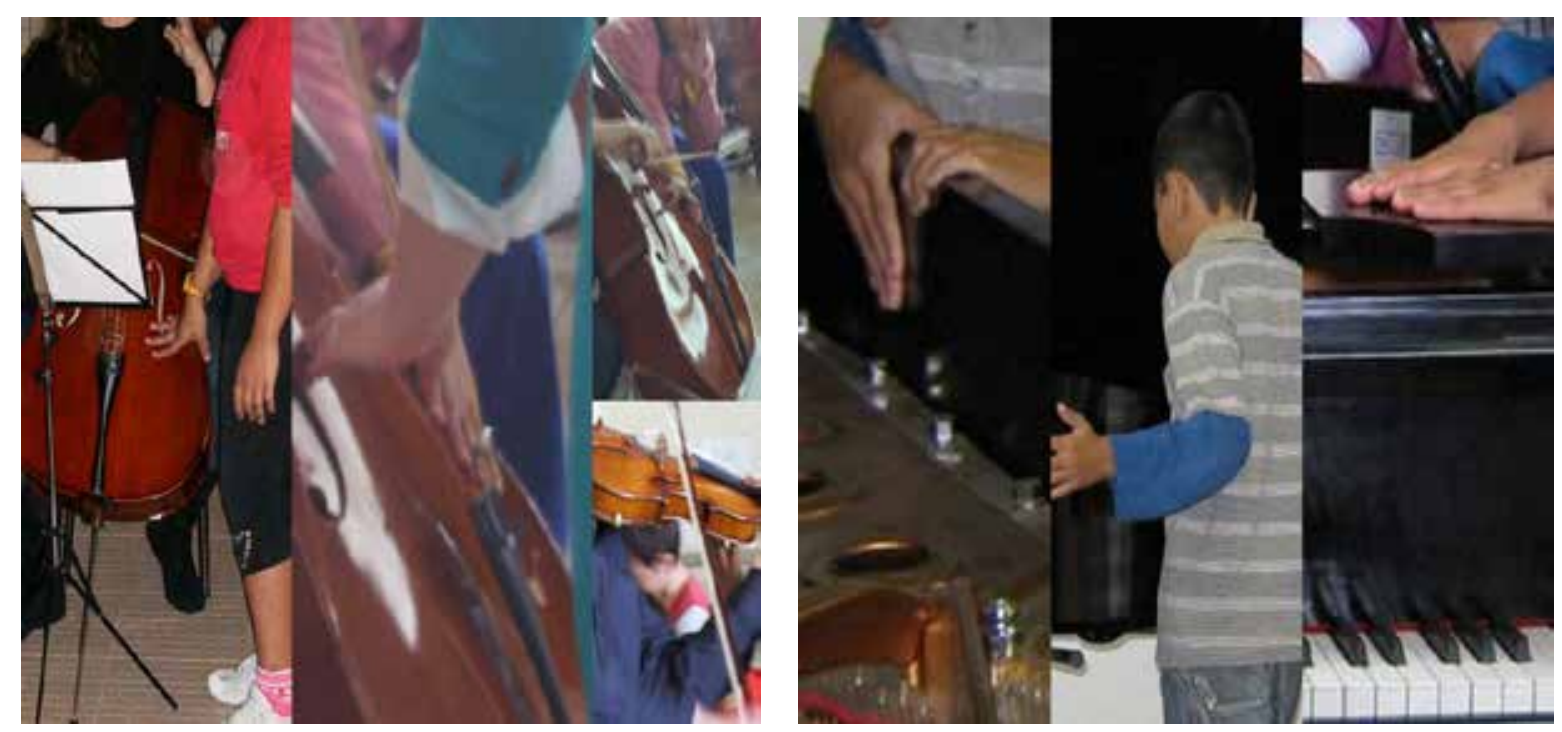

Fig. 1 - Percepção da sensação vibrotátil

Fonte: Acervo da pesquisadora (2009). 
O segundo princípio educativo, experimentação sonora, deu-se no momento em que as crianças organizavam as sonoridades exploradas. Um exemplo foi o desenvolvimento da atividade do conto sonoro, em que os alunos tinham que associar sons aos elementos observados a partir de um passeio pelo entorno da universidade. Com isso, foi possível observar pássaros, vento, pessoas caminhando, movimentação de veículos, entre outros.
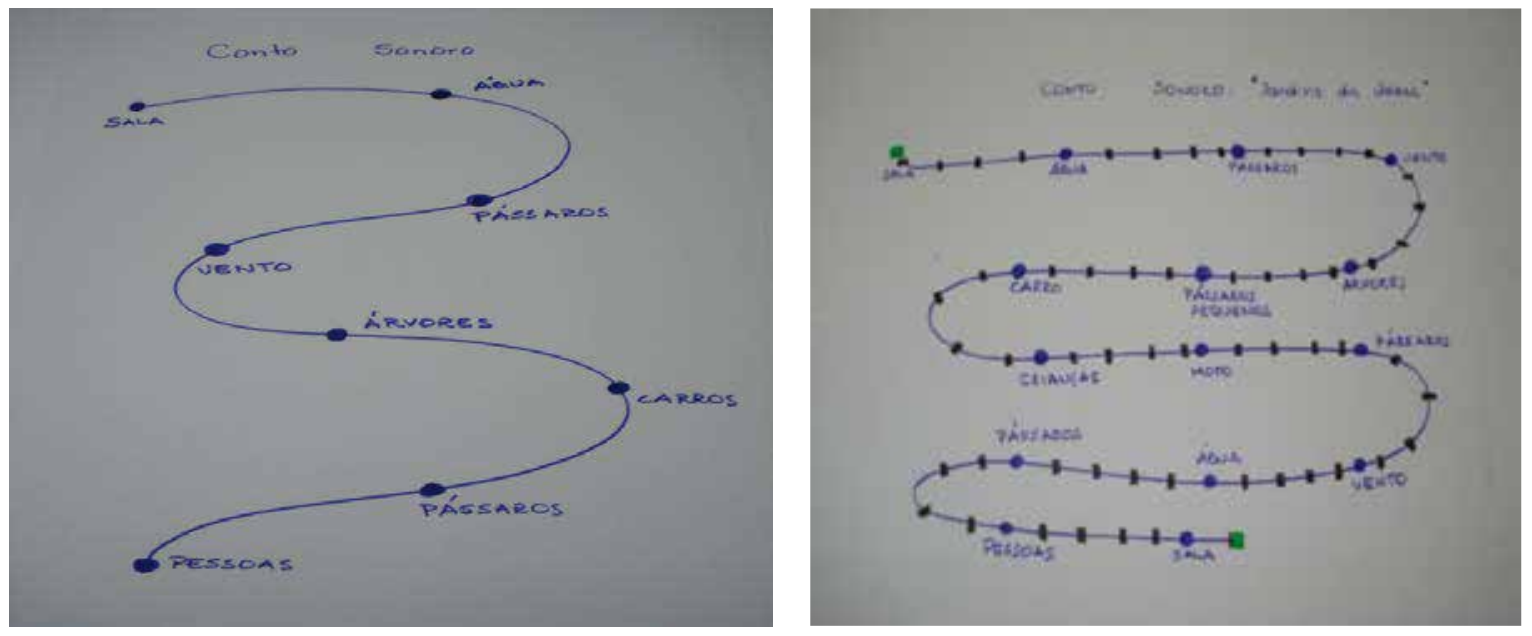

Fig. 2 - Partituras analógicas: 1) Conto sonoro; 2) Jardim da Udesc

Fonte: Elaborada pela autora (2009).

No primeiro momento da construção da partitura analógica Conto Sonoro, foram retratados os elementos sonoros visualizados e mencionados pelo grupo de crianças. Isso foi representado de forma simples, obedecendo-se o itinerário feito com o grupo. Mais tarde, em outro encontro, a partitura retornou para o grupo, agora com elementos musicais acrescidos e, nesse segundo momento, procurou-se representar novos elementos visuais na forma da partitura analógica Jardins da Udesc. Na nova versão da partitura, foram incluídos os elementos de pulso, início e final da peça, além de outras sonoridades que não estavam presentes na primeira versão, conforme demonstrado na Fig. 2. Para interpretar e executar a peça, vários alunos assumiram o papel de condutor/ regente da partitura, e os demais assumiram o papel de músicos executando as sonoridades que foram escolhidas previamente com o grupo.

A estruturação gráfica foi o terceiro princípio educativo usado como eixo norteador das atividades e foi o recurso mais utilizado com o intuito de dar visibilidade às sonoridades exploradas e experimentadas nas duas fases anteriores. O exemplo da Fig. 2 ilustra também esse processo.

Por fim, o quarto princípio educativo, a interpretação (leitura e execução), foi o momento em que os alunos tiveram que atribuir sonoridades para as partituras analógicas criadas e experimentadas anteriormente. Com o passar dos encontros e a utilização dos materiais adaptados, os alunos foram melhorando a qualidade das interpretações e estabelecendo parâmetros para identificar sonoridades, elementos rítmicos, dinâmicas, presença e ausência de som e duração dele. 


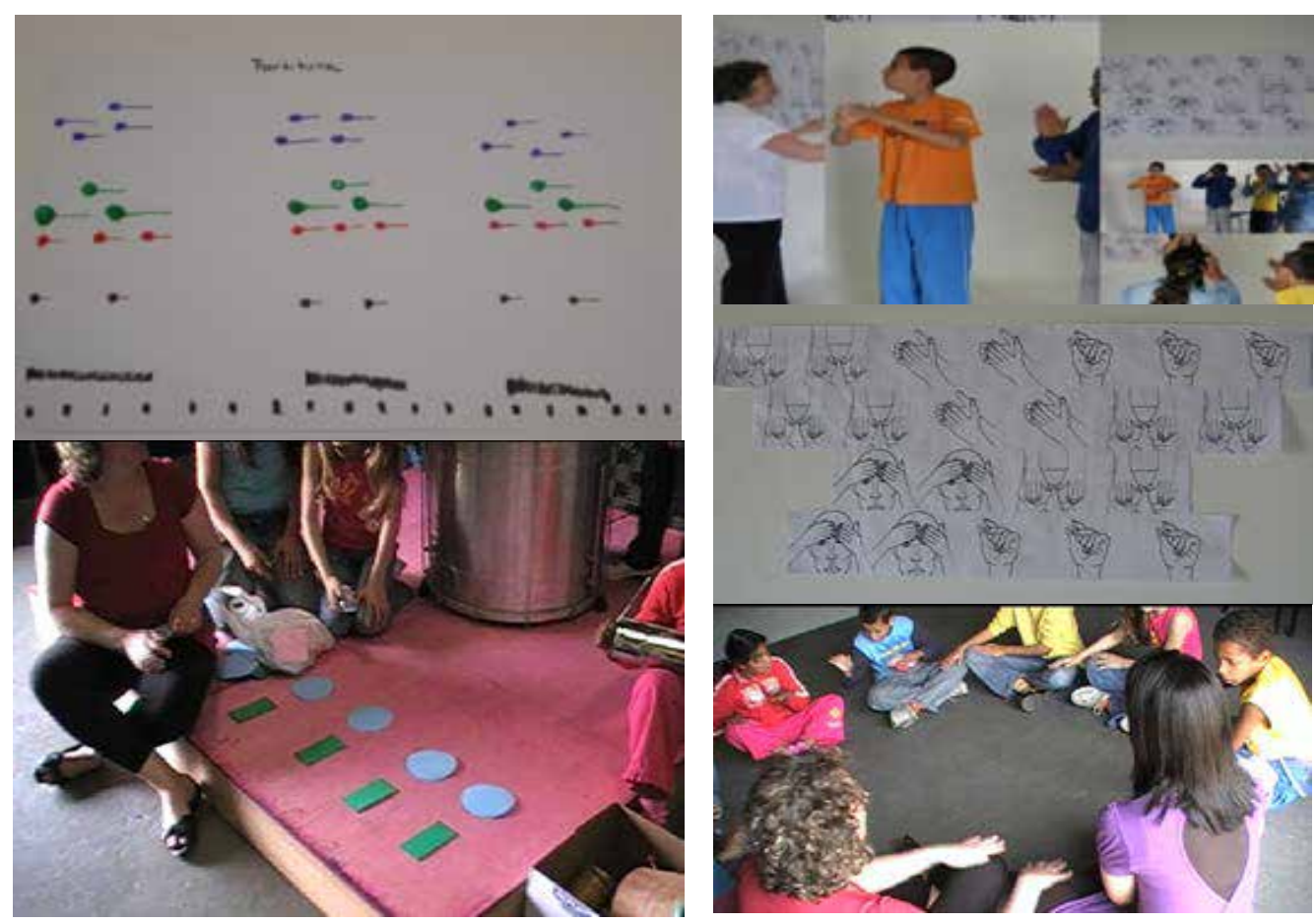

Fig. 3 - Partituras analógicas com base nos parâmetros do som

Fonte: Acervo da autora (2009)

Ao longo das atividades, foram estabelecidos com o grupo mecanismos para a aprendizagem musical. Para as crianças surdas, os conceitos de ouvir e de escutar foram centrais, fazendo emergir um terceiro conceito, o de percepção da sensação vibrotátil.

Destaca-se aqui a atividade com o toque direto nas caixas de ressonância dos instrumentos em audições acústicas. Quando isso não foi possível, a utilização do laptop adaptado com fone de ouvido, que continha o dispositivo bass vibration, foi fundamental.

O dispositivo bass vibration foi basicamente utilizado no jogo da discriminação sonora, idealizado a partir das entrevistas em que alguns professores de alunos surdos e outros professores também surdos afirmaram que alunos com surdez podem fazer discriminação de alguns sons. Os professores entrevistados mencionaram que surdos podiam ouvir sons de motos, ônibus, estrondos de portas e sons de pássaros, por exemplo. Assim, na elaboração de uma primeira versão, 12 sons foram selecionados, sendo representados graficamente e sonorizados. Os sons, para serem escolhidos, partiriam do princípio de que poderiam ser criados pelo homem (culturais) e/ou produzidos pela natureza (naturais). Cada criança poderia repetir a atividade (imagem mais sensação vibrotátil) quantas vezes desejasse, até que a sensação vibrotátil pudesse ser associada e identificada por cada criança. Na fase seguinte do jogo, os sons seriam reconhecidos pela sensação vibrotátil, e não mais pela imagem representada. Identificou-se que nem todos os alunos reconheceram todos os sons reproduzidos, mas ficou claro para esta pesquisadora que os sons mais graves foram facilmente reconhecidos pelo retorno amplificado do dispositivo bass vibration. Diferentemente, os sons mais agudos não foram identificados pela maioria dos alunos surdos. A partir do Jogo de Discriminação Sonora, foi sugerida pelas crianças surdas a elaboração de um novo jogo, agora numa 
versão com os instrumentos musicais. Esse jogo não foi levado adiante, tendo em vista a finalização do projeto. Selecionar instrumentos e fazer as representações gráficas exigiria ainda um tempo maior para a sua estruturação, tempo que não se dispunha, diante do prazo para a finalização da pesquisa.

Por fim, dentro desta seção, estabeleceram-se alguns elementos para a educação musical de alunos surdos, a partir do princípio de que todas as ações musicais desenvolvidas em contexto inclusivo trarão aprendizagens significativas para os alunos surdos somente se houver a preocupação em adaptarem as estratégias de ensino.

\section{ESTRATÉGIAS DE ENSINO ADAPTADAS}

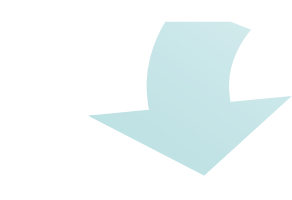

ESPAÇO FÍSICO
MATERIAL DIDÁTICO

\section{ADAPTADO}

Elementos para educação musical de alunos surdos

CONTEÚDOS ADAPTADOS

Fig. 4 - Elementos de educação musical para surdos Fonte: Elaborada pela autora (2009).

As atividades práticas realizadas na oficina com crianças mostraram que os elementos para a educação musical de alunos surdos apontados neste trabalho poderão se constituir como um referencial de apoio para a musicalização de surdos em contexto inclusivo. Ao adaptar as atividades musicais, procurou-se utilizar caminhos alternativos para instigar o crescimento musical dos alunos com surdez.

\section{Considerações finais}

Em comparação aos EUA e países de língua alemã, onde o emprego de música na pedagogia de surdos acontece há mais tempo (ver SALMON 2003, 2006), a tradição em países de língua portuguesa, nesse sentido, é menor, e o seu emprego menos difundido e ainda não completamente documentado - salvo os trabalhos de Haguiara-Cervelini $(1983,2003)$ e de Pereira (2004), no Conservatório Estadual de Música Cora Pavan Capparelli, em Uberlândia/MG.

A fundamentação teórica esclarece temas de desenvolvimento importantes para todas as crianças, mas que são especialmente relevantes para aquelas crianças com comprometimento auditivo. Desse modo, ver, ouvir/sentir e tocar são os princípios norteadores dos processos de musicalização realizados neste trabalho desenvolvido com um grupo de crianças surdas cujas atividades práticas contribuíram para ampliar as dis- 
cussões sobre sua aprendizagem musical, para indicar como se relacionaram com os conteúdos musicais e a forma como eles foram apresentados.

Verificou-se também que, a partir da criação e da utilização de recursos pedagógicos adaptados, foi possível constatar aprendizagens musicais significativas, o que evidencia a possibilidade da estruturação de elementos de ação musical direcionados a crianças surdas em contexto inclusivo.

A partir deste trabalho, pode-se pensar em propostas para o contexto formativo de cursos de Licenciatura em Música e para cursos de Pedagogia, assim como, deste trabalho, já se originaram outros com outros enfoques, mas trazendo para o debate a participação dos surdos em projetos e atividades de música. Portanto, esta pesquisa tem de fato contribuído para mostrar que os processos de musicalização desenvolvidos com os alunos surdos deixaram evidentes as possibilidades de construção de outras realidades. Ratifica-se com este trabalho que a impossibilidade de construir outras realidades reafirmaria ao aluno surdo a sua condição de excluído.

A inserção da música no contexto escolar inclusivo é um princípio de direito que pode ser a única oportunidade de essas crianças terem contato com a linguagem musical e de terem constituído o seu ser musical. Com esse entendimento, o professor, ao dominar os fundamentos da educação musical dos surdos, poderá adaptar com segurança os conteúdos musicais para que esse aluno possa deles apropriar-se. Os desdobramentos técnicos que ele empregará para adaptar esses conteúdos e o seu senso crítico serão fundamentais para a inclusão ou não da música na formação cultural da criança surda.

\section{Referências}

BENARI, Naomi. Inner Rhythm: Dance Training for the Deaf. Performing Arts Studies, v. 3. Harwood Academic Publishers GmbH. Great Britain: Routledge, 2004.

BROWN, Kristi; DENNEY, Le Ann. Music Use in Elementary and Middle School Classrooms for the Deaf. The University of Tennessee, april 4, 1997. Disponível em: <http:// www.deafed.net/PublishedDocs/970723b.htm>. Acesso em: 31 ago. 2017.

CRUZ, A. L. de C. Music For The Deaf: a qualitative approach. In: LABBO, L. D.; FIELD, S. L. (Eds.). 1997. Conference Proceedings of the Qualitative Interest Group. Disponível em: <http://www.coe.uga.edu/quig/Cruz.html>. Acesso em: 29 mar. 2007.

DARROW, A. A.; SCHUNK, H. Music therapy for learners who are deaf/hard- of-hearing. In: WILSON, B. (Ed.). Models of Music Therapy Intervention in School Settings: from institutions to inclusion. Silver Spring, MD: American Music Therapy Association. 1996. p. 200-223. [on line]. Disponível em: <http://musictherapy.fsu.edu/research/darrow. html>. Acesso em: 7 mar. 2007. 
DARROW, Alice-Ann. Teaching Students with Hearing Losses. v. 20, n. 2, p. 27-30, January 1, 2007. DOI: https://doi.org/10.1177/10483713070200020107. Disponível em: <http://journals.sagepub.com/doi/pdf/10.1177/10483713070200020107> Acesso em: 29 ago. 2017.

Music educators' perceptions regarding the inclusion of students with severe disabilities in music classrooms. Journal of Music Therapy, Universidade do Kansas, v. 36, n. 4, p. 254-273, 1999. Disponível em: <http://apt.allenpress.com/aptonline/?request=get-abstract\&issn=0022-2917\&volume=036>. Acesso em: 7 mar. 2007.

EDWARDS, Eleanor M. Music Education for the Deaf. Maine, USA: Merrian-Eddy Company, 1974.

FINCK, Regina. Ensinando música ao aluno surdo: perspectivas para a ação pedagógica inclusiva. 2009. 234 f. Tese (Doutorado em Educação) - Universidade Federal do Rio Grande do Sul, Porto Alegre, 2009.

O fazer criativo em música: um estudo sobre o processo da construção do conhecimento a partir da criação musical. 2001. 148 f. Dissertação (Mestrado em Educação) - Programa de Pós-Graduação em Educação, Faculdade de Educação, Universidade Federal do Rio Grande do Sul, Porto Alegre, 2001.

GLENNIE, Evelin. Preface. In: SALMON, Shirley (Org.). Hören - Spüren - Spielen: Musikund Bewegungmitgehörlosen und schwerhörigenKindern. Tradução Diomara Ziller. Germany: ZeitpunktMusik, 2006. p. 7-10.

Entrevista concedida a Shirley Salomon. In: SALOMON, Shirley. Spiellieder in der multi-sensorischen Förderung von Kindern mit Hörbeeinträchtigungen. Diplomarbeit zur Erlangung eines Magistergrades der Philosophie an der Geisteswissenschaftlichen Fakultät der Leopold-Franzens-Universität Innsbruck, eingereicht bei: a.o. Univ. Prof. Dr. Volker Schönwiese am Institut für Erziehungswissenschaften der Universität Innsbruck, Oktober 2003. Disponível em: <http://bidok.uibk.ac.at/library/salmon-dipl-hoerbeeintraechtigung.html\#id2767859>. Acesso em: 15 ago. 2017.

The Hearing Essay. 2015. [online]. Disponível em: <https://www.evelyn.co.uk/ hearing-essay/>. Acesso em: 03 set. 2017.

HAGUIARA-CERVELLINI, Nadir. A musicalidade do surdo, representação e estigma. São Paulo: Plexus Editora, 2003.

A criança deficiente auditiva e suas reações à música. Dissertação (Mestrado em Ciências - Audiologia) - PUC/SP, São Paulo, 1983.

HASH, Phillip M. Teaching Instrumental Music to Deaf and Hard of Hearing Students. Research and Issues in Music Education, University of Illinois at Urbana/Champaign, v. 1, n. 
1, September 2003. Disponível em: <http://www.stthomas.edu/rimeonline/vol1/hash1. htm>. Acesso em: 6 jul. 2007.

KELLER, Helen. A história de minha vida. Tradução J. Espínola Veiga. Edições Waldorf. Comentários John Macy. São Paulo: Antroposófica, 2001.

LOURO, Viviane S.; ALONSO, Luís G.; ANDRADE, Alex F. de. Educação Musical e deficiência: propostas pedagógicas. São José dos Campos, 2006.

PEREIRA, Sariata Araújo. A utilização de tecnologia para ampliar a experiência sonora/ vibratória de surdos. 2016. 117 f. Dissertação (Programa de Pós-Graduação em Artes) Instituto de Artes da Universidade Federal de Uberlândia, 2016.

. O surdo: caminho para a educação musical. In: 13 Congresso Anual da Associação Brasileira de Educação Musical. Anais... ABEM, Rio de Janeiro, 2004. p. 966-970. ROBBINS, Clive; ROBBINS, Carol. Music for the Hearing Impaired. A resource manual and curriculum guide. St. Louis/Missouri, USA: Magnamusic-Baton, 1980.

SACKS, Oliver. Vendo Vozes: uma viagem ao mundo dos surdos. 5. ed. São Paulo: Companhia das Letras, 2005.

SALMON, Shirley (Org.). Hören - Spüren - Spielen: Musikund Bewegungmitgehörlosen und schwerhörigen Kindern. Trad. Diomara Ziller. Germany: Zeitpunkt Musik, 2006.

Spiellieder in der multi-sensorischen Förderung von Kindern mit Hörbeeinträchtigungen. Diplomarbeit zur Erlangung eines Magistergrades der Philosophie an der Geisteswissenschaftlichen Fakultät der Leopold-Franzens-Universität Innsbruck, eingereicht bei: a.o. Univ. Prof. Dr. Volker Schönwiese am Institut für Erziehungswissenschaften der Universität Innsbruck, Oktober, 2003. Disponível em: <http://bidok.uibk.ac.at/library/salmon-dipl-hoerbeeintraechtigung.html\#id2767859>. Acesso em: 15 mar. 2007. 